\title{
Estimating the spatial extent of bottom-water hypoxia and habitat degradation in a shallow estuary
}

\author{
Christopher P. Buzzelli ${ }^{1, *}$, Richard A. Luettich Jr. ${ }^{1}$, Sean P. Powers ${ }^{1}$, \\ Charles H. Peterson ${ }^{1}$, Jesse E. McNinch ${ }^{2}$, James L. Pinckney ${ }^{3}$, Hans W. Paerl ${ }^{1}$ \\ ${ }^{1}$ University of North Carolina at Chapel Hill, Institute of Marine Sciences, Morehead City, North Carolina 28557, USA \\ ${ }^{2}$ College of William \& Mary, Virginia Institute of Marine Science, Gloucester Point, Virginia 23062, USA \\ ${ }^{3}$ Texas A \& M University, Department of Oceanography, College Station, Texas 77843, USA
}

\begin{abstract}
Bottom-water hypoxia ( $\leq 2 \mathrm{mg} \mathrm{l}^{-1}$ dissolved oxygen [DO]) greatly modifies the benthic habitat of estuaries, depending upon spatial extent, duration, and frequency. Bottom-water hypoxia often develops under conditions of density stratification, which inhibits vertical mixing, and warm temperatures, which enhance biological oxygen demand. Long-term, mid-channel data from the Neuse River Estuary in North Carolina permitted evaluation of how stratification and temperature combined to affect DO concentrations at the bottom. Salinity stratification $(\Delta S)$ and water temperature $(T)$ explained respectively 30 and $23 \%$ of the variance in bottom-water DO concentrations. The amount of salinity stratification required to induce bottom-water hypoxia declined with increasing water temperature. About $80 \%$ of observed hydrographic profiles exhibited bottom hypoxia when $\Delta S$ exceeded $5 \mathrm{psu}$ and $T$ exceeded $20^{\circ} \mathrm{C}$. Using cross-channel hydrographic surveys as verification, we derived a general set of methods to estimate the lateral extent of low-DO bottom water from midchannel hydrographic profiles. The method involves cross-estuary and along-estuary extrapolation based on assumption of a flat oxycline. Occasional violation of this assumption resulted in modest overestimation in cross-channel extent of low DO. Application of this method produced estimates ranging from 0 to $116 \mathrm{~km}^{2}$ of bottom area (0 to $42 \%$ of the estuarine study area) exposed to hypoxia over all sample dates in summer 1997. The maximal bottom area exposed to hypoxia corresponded closely with an independent estimate of the area $\left(100 \mathrm{~km}^{2}\right)$ that experienced almost complete mortality of Macoma spp. clams, the key benthic resource for demersal fishes and crabs. Consequently, mid-channel hydrographic profiles taken along the mid-channel of the estuary can be employed to assess the spatial scale of bottom habitat degradation due to hypoxia.
\end{abstract}

KEY WORDS: Habitat degradation - Hypoxia - Dissolved oxygen - Stratification - Hydrography · Benthos $\cdot$ Macoma spp.

Resale or republication not permitted without written consent of the publisher

\section{INTRODUCTION}

Dynamic patterns of dissolved oxygen (DO) concentrations emerge in estuaries from complex interactions among physical, chemical, and biological processes (Turner et al. 1987, Kemp et al. 1992, Diaz \& Rosenberg

${ }^{*}$ Present address: Duke University Marine Laboratory, Beaufort, North Carolina 28516, USA.

E-mail: buzzelli@duke.edu
1995, Borsuk et al. 2001). Variations in temperature, freshwater discharge, salt-water intrusion, bathymetry, circulation, meteorology, and biological production and respiration combine to produce strong estuarine DO gradients (Falkowski et al. 1980, Stanley \& Nixon 1992, Stanley 1993). Vertical salinity stratification inhibits mixing and helps to stimulate the development of estuarine bottom-water hypoxia and anoxia, particularly in the summer (Stanley \& Nixon 1992). In many estuaries, degradation of organic matter within the water-column 
accounts for a substantial fraction of total oxygen consumption (Matson \& Brinson 1990, Welsh \& Eller 1991, Kemp et al. 1992, Stanley \& Nixon 1992, Hopkinson et al. 1999). However, sediment oxygen demand (SOD) can contribute over $50 \%$ of total respiration in shallower estuaries (average depth $=5 \mathrm{~m}$ ) and rates of SOD often are proportional to rates of nitrogen $(\mathrm{N})$ and phosphorus (P) regeneration (Fisher et al. 1982, Boynton \& Kemp 1985, Rizzo \& Christian 1996). The combination of stratification and water-column and sediment respiration can lead to periodic depletion of bottom-water DO (Officer et al. 1984, Seliger et al. 1985, Rizzo \& Christian 1996, Hopkinson et al. 1999).

In deeper estuaries with considerable flushing, such as lower Chesapeake Bay, gravitational and/or tidal circulation can disrupt stratification and replenish bottom-water oxygen in a matter of hours (Kuo \& Neilson 1987, Kuo et al. 1991). However, shallow estuaries with less frequent flushing often develop persistent stratification, which can lead to benthic hypoxia $\left(\leq 2 \mathrm{mg} \mathrm{l}^{-1}\right.$, see Diaz \& Rosenberg 1995) or anoxia (Tenore 1972, Turner et al. 1987, Lenihan \& Peterson 1998). Although circulation can respond rapidly to changes in freshwater discharge and wind forcing (Breitburg 1990, Sanford et al. 1990, Stanley \& Nixon 1992, Luettich et al. 2000), stratification and bottom-water hypoxia can nonetheless persist for weeks to months (Tenore 1972, Turner et al. 1987, Dortch et al. 1994).

Hypoxia and anoxia degrade bottom habitat through a wide suite of mechanisms. Under conditions of limited oxygen at the bottom, rates of $\mathrm{N}$ and $\mathrm{P}$ remineralization and sulfate reduction increase (Diaz \& Rosenberg 1995, Holmer 1999). The resulting production of sulfide in combination with low oxygen can prove lethal to benthic organisms (Tenore 1972, Diaz \& Rosenberg 1995, Holmer 1999). Because benthic macrofauna serve as essential prey resources for demersal fishes, sustained hypoxia can have significant trophic implications (Pihl et al. 1991, Nestlerode \& Diaz 1998, Peterson et al. 2000, Taylor \& Eggleston 2000). Many fishes migrate away from hypoxic areas in the main estuarine channel to seek refuge in shallower, oxygenated habitats (Pihl et al. 1991, Breitburg 1992, Lenihan et al. 2001). However, wind-driven circulation can rapidly redistribute the hypoxic bottom-water into the shallows (Sanford et al. 1990, Stanley \& Nixon 1992, Luettich et al. 2000), trapping fish and triggering widespread mortality of resident estuarine fishes (Tenore 1972, Paerl et al. 1998). Thus, benthic hypoxia and anoxia can degrade fish habitat and thereby affect the behavior, growth, production, and survival of both benthic invertebrates and mobile vertebrates (Breitburg 1992, Peterson et al. 2000).

Appreciation of the importance of bottom-water hypoxia/anoxia to the production of ecosystem goods and services requires estimation of the spatial extent of the degradation to bottom habitat. One could sample the benthos on a regular basis to detect the scale of habitat degradation. Unfortunately, this empirical approach would require excessive costs for the spatial and temporal coverage necessary. An alternative approach based on an understanding of how oxygen depletion degrades benthic habitat would be to measure DO continuously over a wide area of the bottom. This approach too would prove costly, especially given the demands for maintenance of in situ oxygen sensors. Consequently, we were motivated to apply basic understanding of hydrographic processes to develop a reliable means of estimating the areal coverage by low DO waters based solely on a string of hydrographic profiles taken along the main channel of an estuary. Here we present a simple method to achieve that goal and test its accuracy against cross-channel transects of DO. The ultimate goal may be to develop the first-principles understanding of how nutrient loading, organic loading, and physical forces combine to stimulate hypoxia in an estuary (Cerco \& Cole 1993, Borsuk et al. 2001). Understanding these mechanisms can contribute to better management of riverine and estuarine systems (Nixon 1995, Paerl et al. 1998). Therefore, we also used long-term hydrographic data from the Neuse River Estuary to extract relationships between temperature, stratification, and bottom-water hypoxia that are common to many estuaries. Specifically, we assessed how the effects of stratification on bottom-water DO are dependent upon water temperature.

\section{MATERIALS AND METHODS}

Long-term mid-channel hydrographic surveys. We define the Neuse River Estuary (NRE) as the area between New Bern, NC, and the mouth where it enters Pamlico Sound (Fig. 1). A sharp bend in the NRE splits the estuary into upstream and downstream segments of approximately $35 \mathrm{~km}$. We refer to sampling along the longitudinal axis of the NRE as 'mid-channel' and lateral sampling as 'cross-channel'. All mid-channel locations are numbered by distance in $\mathrm{km}$ from Streets Ferry Bridge (SFB), approximately $15 \mathrm{~km}$ upstream of New Bern (Fig. 1). Cross-channel distances are termed 'widths'.

Hydrographic analyses were made possible by using vertical profiles of temperature $(T)$, salinity $(S)$, and dissolved oxygen (DO) determined at bi-weekly intervals from 1994 to 1998 at 14 mid-channel water quality monitoring stations (Fig. 1; Paerl et al. 1998, Luettich et al. 2000). The stations spanned $42 \mathrm{~km}$ in the longitudinal direction and our analyses included 899 stationdays of hydrographic surveys. At each station on each 


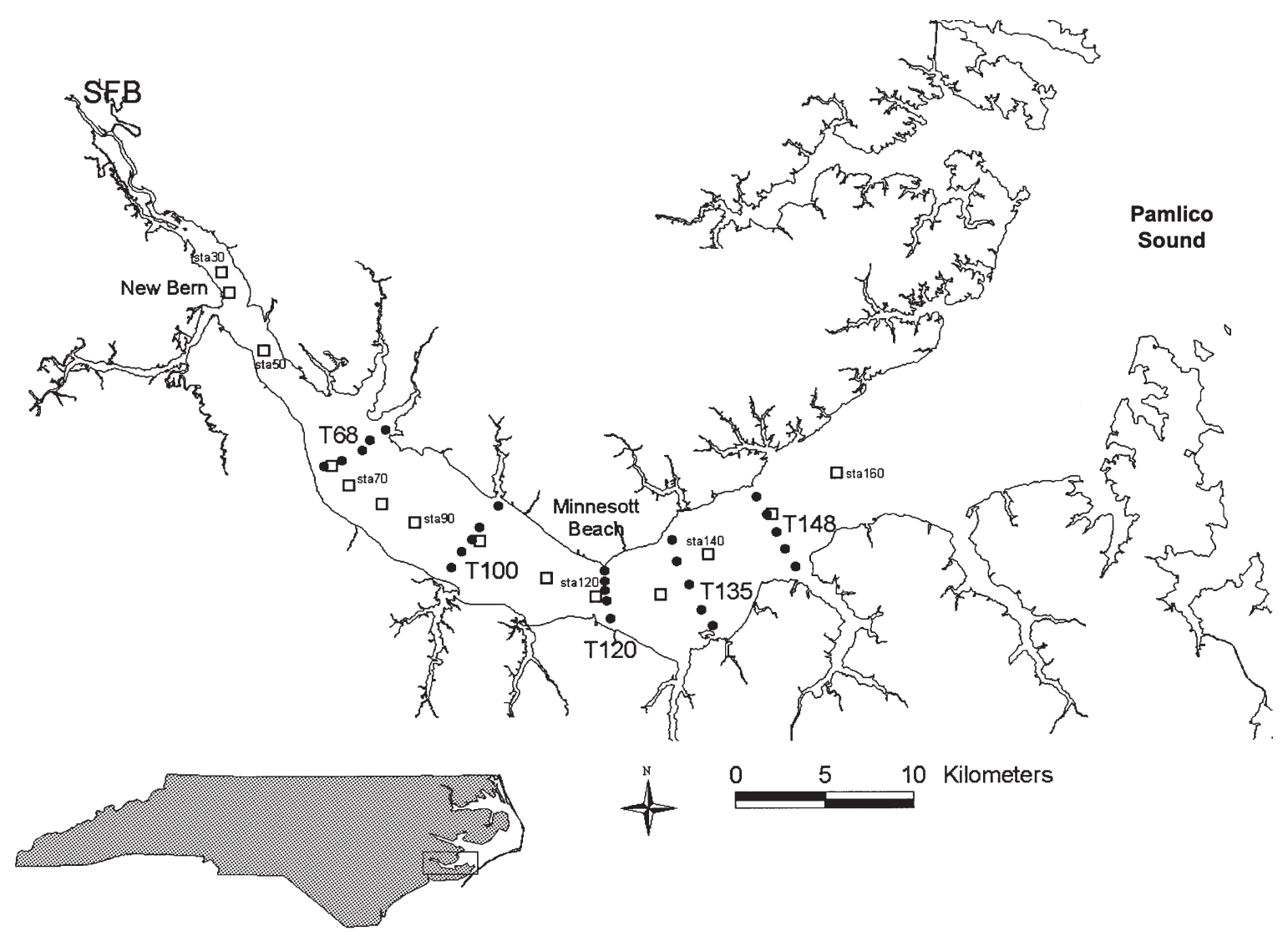

Fig. 1. Mid-channel stations ( $\square$ ) and cross-channel transect locations (•) for hydrographic surveys of the Neuse River Estuary (NRE). Stations and transects are located and labeled relative to Streets Ferry Bridge (SFB; $\left.35.21^{\circ} \mathrm{N}, 77.10^{\circ} \mathrm{W}\right)$, approximately $15 \mathrm{~km}$ upstream from New Bern. The NRE is boxed in the inset map of North Carolina

survey date, values of $T, S$, and DO were recorded at $0.5 \mathrm{~m}$ intervals down to the bottom using a Hydrolab Reporter and Surveyor data logger. For each stationday, we averaged $T$ between surface and bottom, calculated the difference in $S(\Delta S)$ between surface and bottom, and recorded the bottom-water DO. We divided the mid-channel hydrographic data into 3 temperature ranges $\left(0-10,10-20\right.$, and $\left.20-30^{\circ} \mathrm{C}\right)$ and 3 primary $\Delta S$ intervals $(0-2,2-4,>4 \mathrm{psu})$. We first tested the effects of $T, \Delta S$, and their interaction on bottomwater DO concentrations using a 2-way random effects ANOVA. Second, we assessed the relationship between $\Delta S$ (independent) and bottom-water DO concentration (dependent) separately within each of the 3 temperature ranges using linear and non-linear regression. Finally, we calculated for each temperature range the percentage of samples exhibiting bottomwater hypoxia over a series of $6 \Delta S$ intervals $(0-1,1-2$, $2-3,3-4,4-5,>5 \mathrm{psu}$ ) to assess the effects of salinity stratification at a finer resolution.

Intensive along- and cross-channel surveys. Since 1997 was the focus year for intensive along- and crosschannel hydrographic surveys, we assessed the overall spatial and temporal patterns of water column stratification and bottom-water hypoxia in the mid-channel data for that year. We generated space-time maps of these 2 variables using a kriging interpolation routine (Bonham-Carter 1994, Surfer 1999). The spatial boundaries for this analysis included all the stations from SFB to Stn 160 located $57 \mathrm{~km}$ downstream (Fig. 1). Midchannel hydrographic sampling did not begin in the downstream segment until June 1997, the same time that the intensive surveys started. We used these maps to identify patterns of stratification and hypoxia within the area from June through October 1997.

To estimate the spatial coverage by low-DO bottom water, we developed a simple method of extrapolation from a series of hydrographic profiles at mid-channel stations. At each individual station, the cross-channel extent of low DO was estimated by lateral extrapolation of oxygen concentrations at depth. We chose concentrations of both 4 and $2 \mathrm{mg} \mathrm{l}^{-1}$ for our analyses, corresponding to the thresholds that induce fish emigration (Tyson \& Pearson 1991) and invertebrate stress (Diaz \& Rosenberg 1995) respectively. We use the terms 'oxygen-stressed' and 'hypoxic', to identify these 
Table 1. Transect labels (T), distance ( $d$ in $\mathrm{km}$ ) downstream from Streets Ferry Bridge, and dates (1997) for cross-channel studies of the Neuse River Estuary to assess near-bottom DO concentrations. An X indicates that a transect was sampled on a particular day while an empty cell signifies that the transect was not sampled. The superscript values of 4 and 2 indicate DO concentrations of $\leq 4$ or $\leq 2 \mathrm{mg} \mathrm{l}^{-1}$, respectively

\begin{tabular}{|cccccccccccccccc}
\hline $\mathrm{T}$ & $d$ & Jul 15 & Jul 21 & Jul 29 & Aug 4 & Aug 12 & Aug 19 Aug 27 & Sept 8 & Sept 17 & Oct 1 & Oct 7 & Total all & Total $\leq 4$ & Total $\leq 2$ \\
\hline 68 & 24 & $\mathrm{X}^{4}$ & $\mathrm{X}^{2}$ & & $\mathrm{X}^{2}$ & $\mathrm{X}^{2}$ & $\mathrm{X}^{2}$ & $\mathrm{X}^{2}$ & $\mathrm{X}^{4}$ & $\mathrm{X}^{2}$ & & $\mathrm{X}^{2}$ & 9 & 9 \\
100 & 32 & $\mathrm{X}^{2}$ & & $\mathrm{X}^{2}$ & $\mathrm{X}^{2}$ & $\mathrm{X}$ & $\mathrm{X}^{2}$ & $\mathrm{X}$ & $\mathrm{X}^{4}$ & $\mathrm{X}^{2}$ & $\mathrm{X}^{4}$ & $\mathrm{X}^{4}$ & 10 & 8 & 5 \\
120 & 40 & $\mathrm{X}^{2}$ & $\mathrm{X}^{2}$ & $\mathrm{X}^{2}$ & $\mathrm{X}$ & $\mathrm{X}$ & $\mathrm{X}^{2}$ & $\mathrm{X}$ & $\mathrm{X}^{4}$ & & $\mathrm{X}$ & $\mathrm{X}^{4}$ & 10 & 6 & 4 \\
135 & 45 & $\mathrm{X}^{4}$ & $\mathrm{X}^{2}$ & $\mathrm{X}^{2}$ & $\mathrm{X}$ & $\mathrm{X}^{4}$ & $\mathrm{X}^{2}$ & & $\mathrm{X}^{4}$ & $\mathrm{X}^{2}$ & $\mathrm{X}$ & $\mathrm{X}^{4}$ & 10 & 8 & 4 \\
148 & 50 & $\mathrm{X}^{4}$ & & $\mathrm{X}^{2}$ & & $\mathrm{X}$ & & & $\mathrm{X}$ & $\mathrm{X}^{2}$ & $\mathrm{X}$ & & 6 & 3 & 2 \\
Total & & & & & & & & & & & & & 45 & 34 & 22 \\
\hline
\end{tabular}

2 levels. The lateral extrapolation of each low-DO contour terminated when it intersected the bottom, thereby defining the linear cross-channel width of bottom exposed to low DO. The primary assumption for this method is that there is no lateral tilt to the oxycline. To apply our linear estimates of cross-channel low-DO to estimate areal coverage, we used line segments to connect the ends of each pair of adjacent cross-channel widths. This procedure generated polygons representing the area exposed to hypoxia. The line segments used were straight even though the true bathymetry would imply some small curvature to the margins. However, the curvature for the NRE would be modest, and thus this approximation introduced minimal error.

To verify the accuracy of our extrapolation method, we compared the estimated cross-channel widths of low-DO extent to interpolations based on multiple pro-

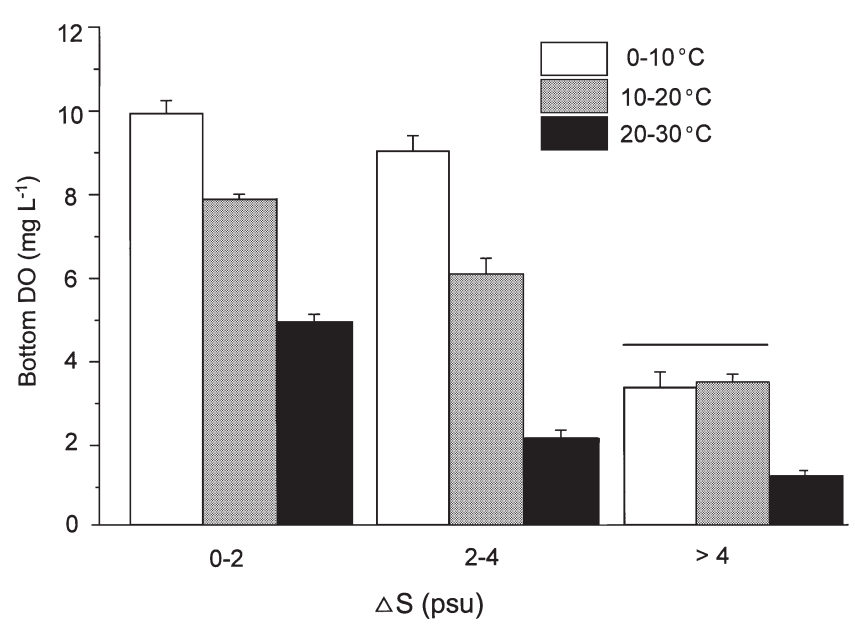

Fig. 2. Bar plot of statistical effects of temperature range $\left(0-10,10-20,20-30^{\circ} \mathrm{C}\right)$ and $\Delta S$ interval $(0-2,2-4,>4 \mathrm{psu})$ on bottom-water DO concentrations (mean $+1 \mathrm{SE}$ ) using all hydrographic data from 14 mid-channel stations between 1994 and 1998 ( $\mathrm{n}=899$ ). The horizontal bar connects mean DO concentrations that were statistically indistinguishable (Scheffe's post hoc contrast, $\mathrm{p}>0.05$ ). All other mean values were significantly different $(p<0.0001)$ files of observed oxygen concentrations taken on each of several cross-channel transects. Cross-channel hydrographic surveys were conducted on 10 dates between 15 July and 7 October 1997 (Table 1). Generally, on each day we obtained a hydrographic profile at each of 5 stations along 5 transects (T68, T100, T120, T135, T148; Fig. 1) using a Sea-Bird CTD with attached flow-through system and DO sensor (Table 1). We produced cross-channel DO contour maps for each transect-day using a kriging interpolation routine (Bonham-Carter 1994, Surfer 1999). On the maps, we located where the $\leq 4$ and $\leq 2 \mathrm{mg} \mathrm{l}^{-1}$ contour lines intersected with the bottom on both sides of the estuary and measured the widths. We conducted separate comparisons of methods using $\leq 4$ or $\leq 2 \mathrm{mg} \mathrm{l}^{-1}$ thresholds to provide tests at different depths in the profile (Table 1). We compared the 2 different methods for estimating cross-channel widths of low-DO water by a goodness of fit test in which we measured the variance explained by, and assessed the distribution of residuals around, the identity line of $y=x$.

\section{RESULTS}

\section{Long-term mid-channel hydrographic surveys}

Depth-averaged $T, \Delta S$, and the $T \times \Delta S$ interaction each significantly (in all cases, p < 0.0001) affected average bottom-water DO concentrations in the NRE (Fig. 2). $T$ and $\Delta S$ accounted for 23 and $30 \%$, respectively, and the interaction $3 \%$ of the variance in bottom-water DO concentrations across dates between 1994 and 1998. The temperature effect on DO concentration was significant within each of the $3 \Delta S$ intervals of $0-2,2-4$ and $>4$ psu (Fig. 2). DO concentrations differed significantly among the $0-10,10-20$, and $20-30^{\circ} \mathrm{C}$ temperature ranges when $\Delta S$ was $0-2$ or 2-4 psu (Fig. 2). There was no difference, however, in mean DO concentrations among the 0-10 and $10-20^{\circ} \mathrm{C}$ ranges when $\Delta S$ was $>4$ psu, but the mean DO concentrations for these temperature classes were 
significantly greater than those in the $20-30^{\circ} \mathrm{C}$ range (Fig. 2).

The relationships between $T, \Delta S$, and hypoxia are illustrated with fine resolution by compiling data on the frequency of hypoxia in the mid-channel hydrographic observations. Even with temperature in the 0$10^{\circ} \mathrm{C}$ range, $58 \%$ of the samples exhibited bottomwater hypoxia when $\Delta S$ was $>5$ psu (Fig. 3). Under conditions of less intense salinity stratification, however, no incidence of hypoxia occurred in the $0-10^{\circ} \mathrm{C}$ range. Bottom-water hypoxia appeared at $10-20^{\circ} \mathrm{C}$ when $\Delta S$ was between 2 and 5 psu, but only when salinity stratification exceeded 5 psu did $60 \%$ of the bottom-water samples exhibit hypoxia (Fig. 3). At the highest water temperatures of $20-30^{\circ} \mathrm{C}$, only a $1-2 \mathrm{psu}$ stratification was required to induce hypoxia in $40 \%$ of the samples, with incidence increasing to $80 \%$ as $\Delta S$ exceeded 5 psu (Fig. 3).

Over all temperature ranges, bottom-water DO concentrations decreased with increasing $\Delta S$ (Fig. 4). As temperature increased, the curves relating DO to salinity stratification shifted towards the origin and less stratification was required to achieve low DO. The relationship between $\mathrm{DO}$ and $\Delta S$ in the $0-10^{\circ} \mathrm{C}$ range was linear with $\mathrm{r}^{2}=0.74(\mathrm{p}<0.001$; Fig. 4A). In the 20$30^{\circ} \mathrm{C}$ range (Fig. 4C), a non-linear decline fit better than the linear response $\left(r^{2}=0.60\right.$ vs $\left.0.43 ; p<0.001\right)$. For the intermediate temperatures of $10-20^{\circ} \mathrm{C}$, linear $\left(\mathrm{r}^{2}=0.48 ; \mathrm{p}<0.001\right)$ and non-linear regressions $\left(\mathrm{r}^{2}=\right.$ $0.50 ; \mathrm{p}<0.001$ ) fit equally well (Fig. 4B). With increasing water temperatures, near-zero oxygen concentrations were approached at lower levels of stratification, leading to co-linearity or existence of an asymptote in the relationship.

\section{Intensive along- and cross-channel surveys}

During the warm-water months of June through October 1997, long stretches of the mid-channel in the NRE exhibited $\Delta S$ of 2 to 8 psu and DO concentrations at or below the hypoxic threshold (Fig. 5). Over $40 \mathrm{~km}$ of the NRE mid-channel water possessed $\Delta S>2 \mathrm{psu}$ throughout much of July (Fig. 5A). DO concentrations below $2 \mathrm{mg} \mathrm{l}^{-1}$ first appeared in the bottom water in late June, and by mid-July a large lens of hypoxic bottom water extended from the 10 to the $45 \mathrm{~km}$ points downstream of the SFB (Fig. 5B). The water column from 5 to $40 \mathrm{~km}$ downstream was stratified for the first $2 \mathrm{wk}$ of August (2-8 psu), whereas isolated patches of stratified water centered at 15 and $57 \mathrm{~km}$ downstream occurred later in August (Fig. 5A). Patches of oxygenstressed waters occurred near 30 and $45 \mathrm{~km}$ downstream, and much of the bottom-water between 5 and $20 \mathrm{~km}$ was hypoxic for most of August (Fig. 5B). Con-

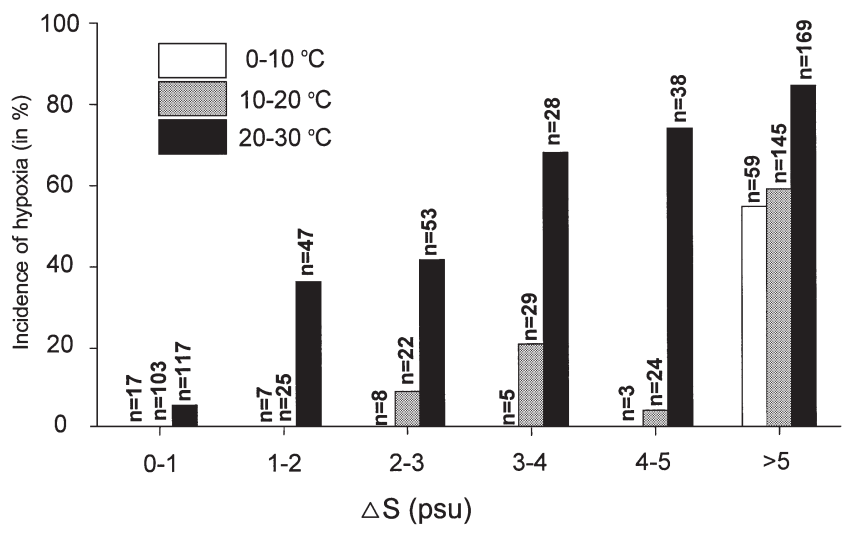

Fig. 3. Percentage of samples with bottom-water hypoxia $(\leq 2$ $\mathrm{mg} \mathrm{l}^{-1}$ ) over different combinations of $T$ and $\Delta S$ (total $\mathrm{n}=899$ ). For example, $36 \%$ of the samples $(17 / 47)$ in the $20-30^{\circ} \mathrm{C}$ range with $\Delta S$ values of 1-2 psu had DO concentrations $\leq 2 \mathrm{mg} \mathrm{l}^{-1}$
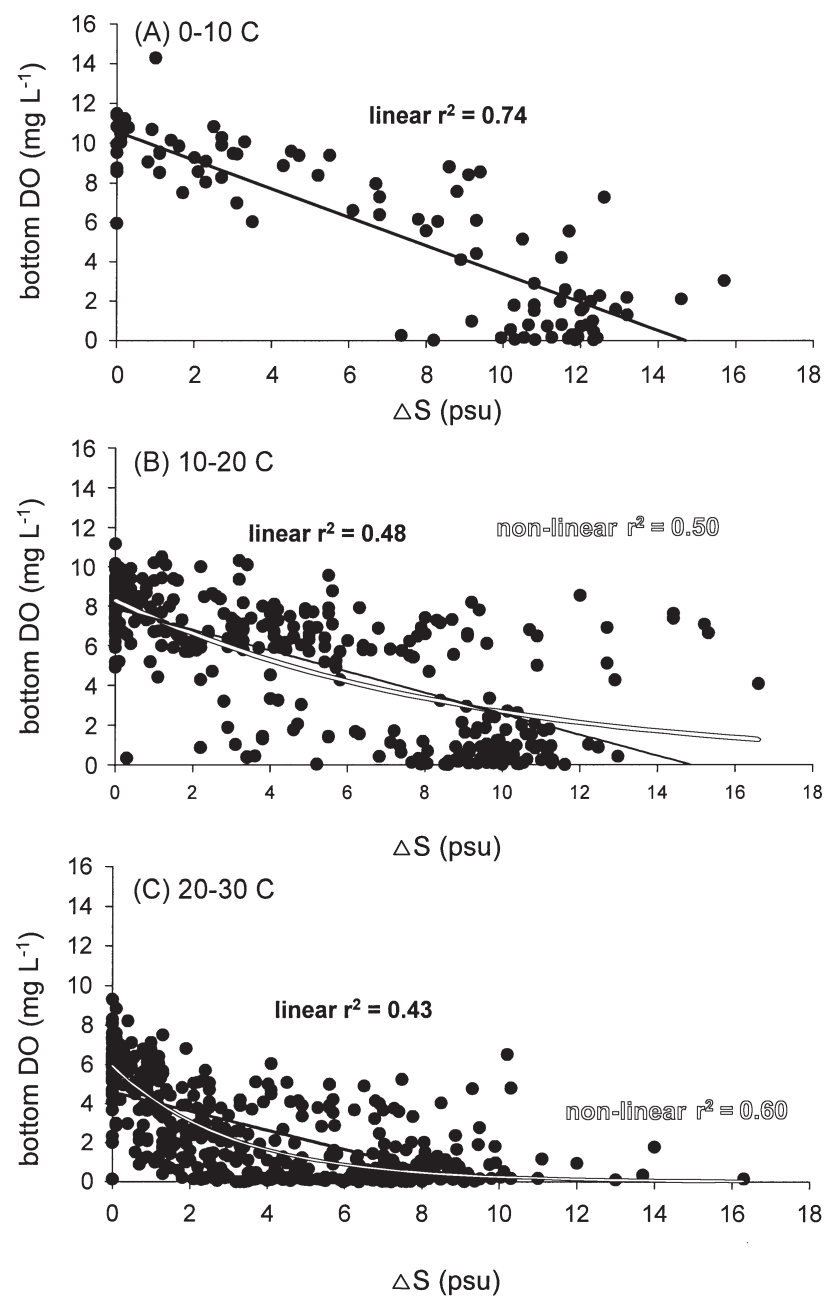

Fig. 4. Regressions of bottom DO concentrations and $\Delta S$ from the 14 mid-channel hydrographic stations. (A) Linear regression for the $0-10^{\circ} \mathrm{C}$ range $(\mathrm{n}=99)$; (B) Linear and non-linear regressions for the $10-20^{\circ} \mathrm{C}$ range $(\mathrm{n}=348),(\mathrm{C})$ Linear and non-linear regression for the $20-30^{\circ} \mathrm{C}(\mathrm{n}=452)$ 


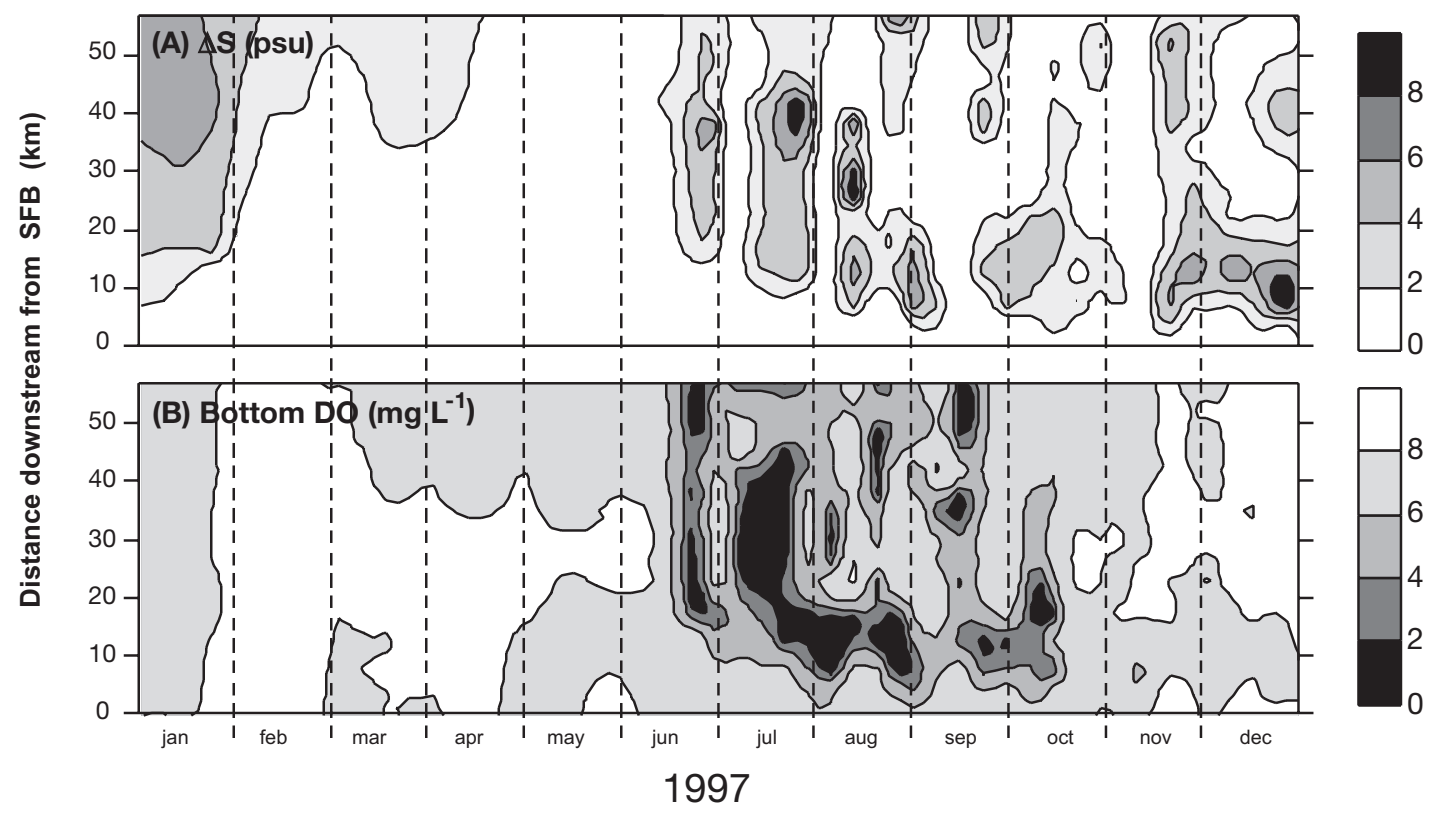

Fig. 5. Spatial and temporal contour plots of (A) $\Delta S$ and (B) bottom-water DO concentrations in the Neuse River Estuary in 1997. The vertical axis is distance downstream from SFB and extends to Oriental, NC, approximately $57 \mathrm{~km}$ downstream. Both $\Delta S$ and bottom-water DO concentrations have the same contour intervals $(0-2,2-4,4-6,6-8,>8)$, but the shading order was reversed to emphasize high $\Delta S$ and low DO

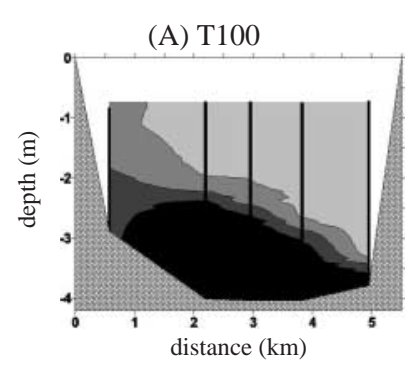

(E) T68

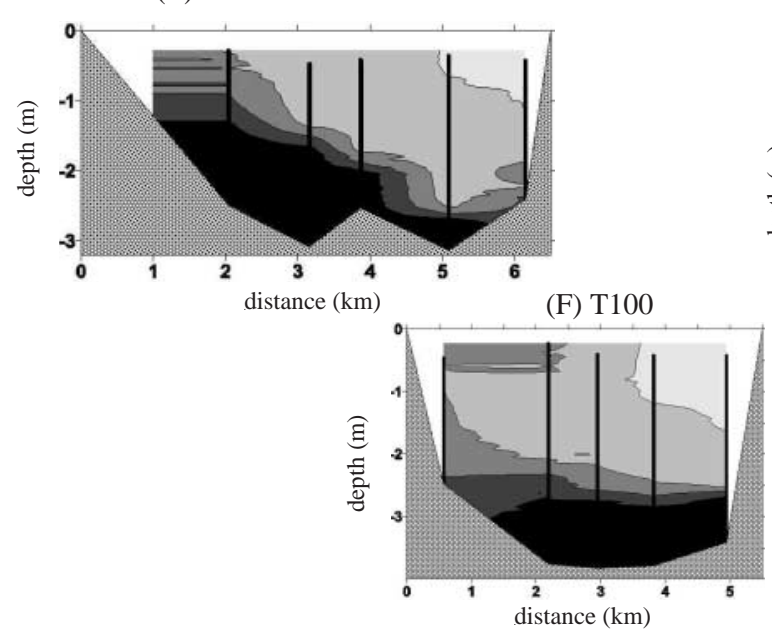

(C) T135
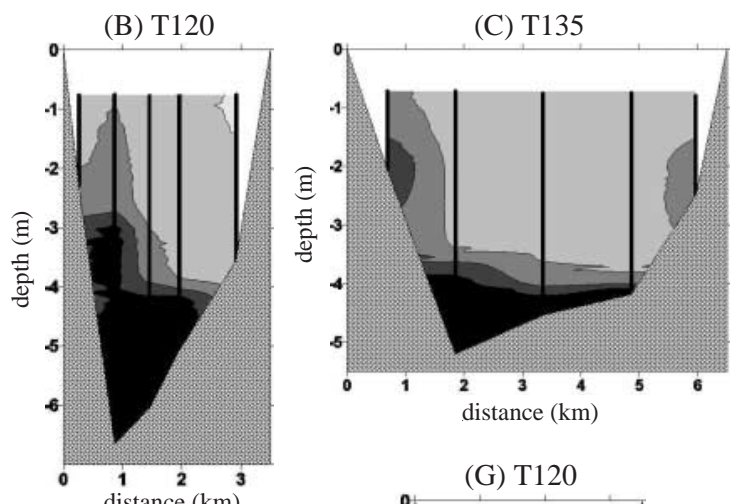

(G) T120

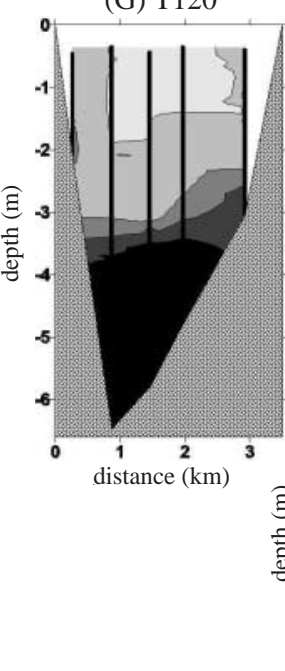

(D) $\mathrm{T} 148$
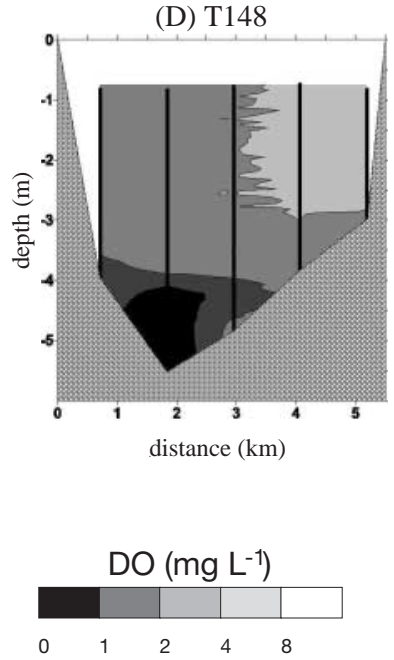

(H) T135

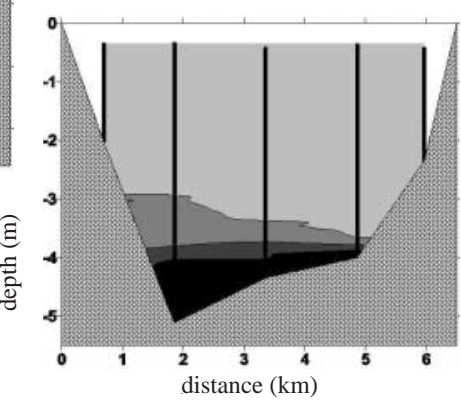

Fig. 6. Cross-channel DO contours derived from cross-channel hydrographic transects (noted as T in Fig. 1) at 4 different locations. (A-D) 29 July 1997; (E-H) 19 August 1997. Each contour plot looks downstream with depth (m) as the $y$-axis and crosschannel distance from the north shore $(\mathrm{km})$ as the $x$-axis. The plots were scaled proportionally to demonstrate variations in the depth and width of the NRE at each of the cross-channel locations 
siderable vertical salinity stratification $(2-4$ psu $)$ existed in September in both upstream (5-20 km) and downstream $(35-57 \mathrm{~km})$ segments and into October near $15 \mathrm{~km}$ downstream. Bottom-water DO concentrations were 4-6 $\mathrm{mg} \mathrm{l}^{-1}$ in September except for patches of hypoxia from $30-50 \mathrm{~km}$ in the middle of the month. DO concentrations $\leq 4 \mathrm{mg} \mathrm{l}^{-1}$ existed $5-35 \mathrm{~km}$ downstream in the NRE through the end of September and persisted into mid-October (Fig. 5B).

Cross-channel contour maps constructed from our hydrographic transects during a period of intense oxygen depletion (29 July and 19 August 1997) revealed the extent and complexity of DO distributions (Fig. 6). On both days the $\leq 2 \mathrm{mg} \mathrm{l}^{-1}$ DO lens at T100 $(32 \mathrm{~km}$ downstream) was at least $1.0 \mathrm{~m}$ thick and several $\mathrm{km}$ wide (Fig. 6A,F). Although we did not sample T68 (24 km downstream) on 29 July, considerable hypoxic bottom-water occurred at this location on 19 August (Fig. 6E). On both days there was a large amount of deep, oxygen-stressed bottom-water at T120 $(40 \mathrm{~km}$ downstream), located near the bend in the NRE (Fig. 6B, G; see Fig. 1). Downstream of this location at T135 (45 km downstream), the $\leq 4 \mathrm{mg} \mathrm{l}^{-1}$ DO bottomwater extended approximately $3 \mathrm{~km}$ laterally on both days (Fig. 6C,H).

The comparisons of our 2 methods for estimating the cross-channel width of oxyclines confirmed the utility of extrapolating from mid-channel profiles, while simultaneously revealing limitations. Estimates of the

Table 2. Estimated areal coverage of bottom-water hypoxia ( $\leq 2 \mathrm{mg} \mathrm{l}^{-1} \mathrm{DO}$ ) in the Neuse River Estuary from June through September 1997. These estimates were derived by extrapolating laterally from the mid-channel $\leq 2 \mathrm{mg} \mathrm{l}^{-1}$ DO concentrations at each of the 14 stations shown in Fig. 1 using the method developed in this study. The total size of the study area was approximately $277 \mathrm{~km}^{2}$

\begin{tabular}{|lcc|}
\hline $\begin{array}{l}\text { Date } \\
\text { 1997) }\end{array}$ & $\begin{array}{c}\text { Estimated } \\
\text { area }\left(\mathrm{km}^{2}\right)\end{array}$ & $\begin{array}{c}\text { Percent of } \\
\text { study area (\%) }\end{array}$ \\
\hline 10 Jun & 0.00 & 0.0 \\
24 Jun & 97.1 & 35.1 \\
1 Jul & 9.4 & 3.4 \\
8 Jul & 69.8 & 25.2 \\
15 Jul & 14.3 & 5.2 \\
22 Jul & 116.5 & 42.1 \\
30 Jul & 11.9 & 4.3 \\
7 Aug & 15.9 & 5.8 \\
12 Aug & 11.8 & 4.3 \\
20 Aug & 53.2 & 19.2 \\
26 Aug & 6.4 & 2.3 \\
2 Sep & 102.9 & 37.2 \\
9 Sep & 4.2 & 1.5 \\
16 Sep & 2.4 & 0.9 \\
23 Sep & 13.8 & 5.0 \\
30 Sep & 2.8 & 1.0 \\
Average & 35.5 & 12.8 \\
\hline
\end{tabular}
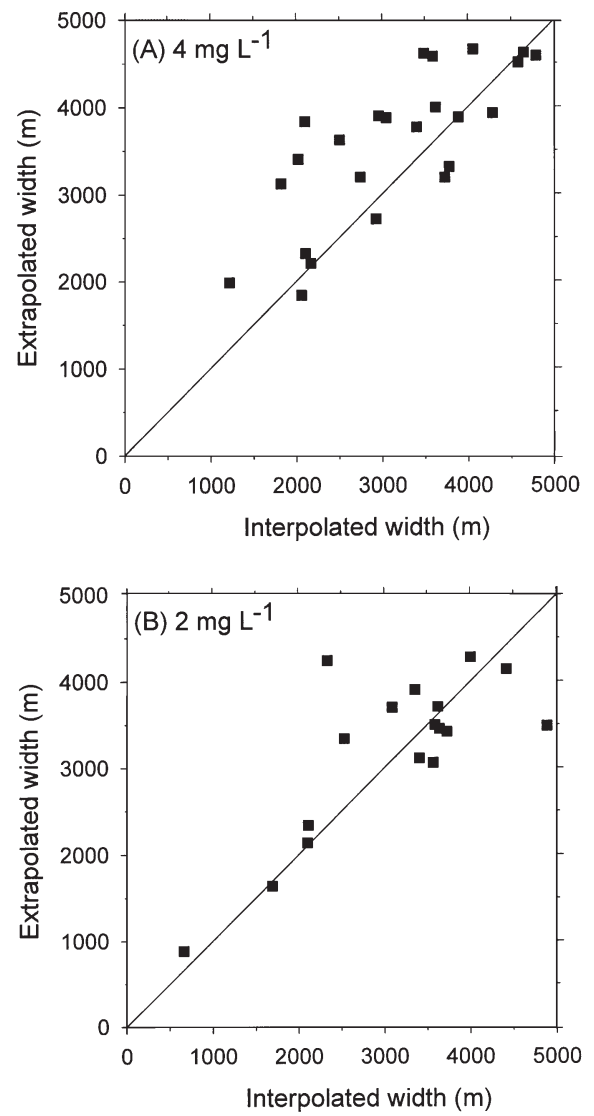

Fig. 7. Relationship between cross-channel DO contour widths extrapolated from the mid-channel $(y)$ vs verification widths derived from a series of 5 profiles $(x)$. The identity line $(y=x)$ accounted for a significant fraction of the variance for both the $\leq 4 \mathrm{mg} \mathrm{l}^{-1}\left(\mathrm{~A}, \mathrm{r}^{2}=0.23, \mathrm{p}=0.01\right)$ and the $\leq 2 \mathrm{mg} \mathrm{l}^{-1}(\mathrm{~B}$, $\left.r^{2}=0.43, p<0.01\right)$ DO contour classes

lateral extent of the $4 \mathrm{mg} \mathrm{l}^{-1}$ DO oxycline were similar, such that the regression fit to the identity line $(y=x)$ was significant $(p<0.01)$. However, the variance explained by the line was only $23 \%$ (Fig. 7A). A tendency for the extrapolation method to overestimate the widths of the $4 \mathrm{mg} \mathrm{l}^{-1}$ contour by an average of $20 \%$ was marginally non-significant in a sign test comparing the numbers of points falling above and below the line $(p=0.08)$. The tendency to overestimate the widths of the $2 \mathrm{mg} \mathrm{l}^{-1}$ contour was smaller $(10 \%)$ and again non-significant (sign test, $\mathrm{p}=0.17$ ). The identity line explained $43 \%$ of the variance (Fig. 7B).

We used our extrapolation method along with the mid-channel profile data from summer 1997 to estimate the areal extent of benthic hypoxia in the NRE on 15 dates from June to September. Hypoxic area averaged $35.5 \mathrm{~km}^{2}$ (Table 2). The maximal areas covered by hypoxic bottom waters were estimated to be $97.1,69.8$, $116.5,53.2$, and $102.9 \mathrm{~km}^{2}$ on 24 June, 8 July, 22 July, 
20 August, and 2 September 1997, respectively (Table 2). The estimated area ranged from 0.0 to $15.9 \mathrm{~km}^{2}$ in the other weeks. The percentage of the study area that suffered benthic hypoxia in the summer of 1997 was greater than $35 \%$ on sampling days in June, July, and September and averaged 12.8\% (Table 2).

\section{DISCUSSION}

A mechanistic understanding of spatio-temporal dynamics in bottom-water DO concentrations in estuaries requires synthesis of physical, biological, and chemical processes (Welsh \& Eller 1991, Kemp et al. 1992). Vertical density stratification inhibits penetration of oxygenated surface waters into the bottom layers independent of season and temperature. However, higher temperatures elevate biological rates and facilitate microbial depletion of DO in the water column and sediments (Turner et al. 1987, Welsh \& Eller 1991, Stanley \& Nixon 1992, Rabalais et al. 1994). Consequently, $\Delta S$ and $T$ are the most important variables contributing to variation in bottom-water DO concentration, as illustrated by our analysis of DO in the NRE (Fig. 2). We extended the understanding of how these 2 factors work together by exploring the nature of a significant interaction that emerged from our analysis. By separating the $T$ data into 3 ranges $(0-10,10-20$, and $20-30^{\circ} \mathrm{C}$ ), we were able to demonstrate that even in the lowest $T$ range oxygen demand was sufficient to induce hypoxia provided that stratification was intense enough (Fig. 3). In the NRE, reserves of organic matter stored in the sediments are sufficient to fuel microbial degradation even in the cold months of the year. Luettich et al. (2000) calculate that, absent of any new inputs, multiple years would be required to respire the existing sedimentary pools of organic matter in the NRE.

The positions and shapes of the curves relating DO to intensity of stratification differed among the $3 \mathrm{~T}$ ranges (Fig. 4), providing further insight into the ways in which these 2 factors interact. As $T$ increased, less intense salinity stratification was required to induce any given level of oxygen depletion. Thus, the curves were shifted towards the origin with increasing $T$ (Fig. 4). This shift produced a change from a purely linear relationship of DO to $\Delta S$ at the lowest $T$ range to what appeared to be an exponentially declining relationship at the highest T. Borsuk et al. (2001) used intensity of stratification as an estimate of time since the last mixing event in modeling DO dynamics of the NRE to estimate rates of DO consumption. Using this assumption that $\Delta S$ represents a good proxy for time since mixing, our segregation of the data into separate
$T$ ranges implies that oxygen depletion could be modeled with a family of curves for different times of the year.

Our simple method to estimate cross-channel widths of low-DO waters by extrapolating from mid-channel profiles proved promising. The verification of the method using 5 cross-channel profiles revealed a general agreement but with substantial unexplained variance (Fig. 7). Furthermore, the extrapolation method appeared to overestimate the cross-channel widths, although the overestimates were not statistically detectable. Examination of the DO contours estimated from the series of cross-channel transects uncovered occasional departures from the central assumption of a flat, linear oxycline emanating away from the midchannel. Departures were of 2 primary, interrelated types, both of which were more evident towards the shores (Fig. 6). First, some contours exhibited convexity at the ends of the contours, where they intersected the bottom (Fig. 6A). Such departures from the linearity assumption clearly result in overestimation of the actual contour widths. This pattern is a likely consequence of enhanced mixing that occurs through local upwelling and downwelling interactions with the shoreline (Luettich et al. 2000). Because the $\leq 2 \mathrm{mg} \mathrm{l}^{-1}$ DO contour is deeper and shorter in width than the $\leq 4 \mathrm{mg} \mathrm{l}^{-1}$ DO contour, the effects of interaction with the shoreline are less. This can explain why the fit between empirical measurements and extrapolated estimates are better for the $\leq 2 \mathrm{mg} \mathrm{l}^{-1}$ contour (Fig. 7). Second, other contours revealed a (wind-driven) tilt across the channel (Fig. 6B), resulting in greater error in estimation of the contour widths. Reversals in wind direction due to the passage of meteorological fronts can trigger cross-estuary sloshing events that redistribute the main channel water, leading to dynamic patterns of DO on hourly-daily time scales (Sanford et al. 1990, Stanley \& Nixon 1992, Luettich et al. 2000).

Our intent in developing a simple method for estimating the cross-channel width of low-DO water in the estuary was to permit estimation of the total bottom area exposed. Estimates of the bottom habitat exposed to hypoxia in summer 1997 (Table 2) corresponded well with the area of bottom habitat shown to exhibit dramatic decreases in benthic fauna during this same time interval. The abundance and biomass of Macoma balthica amd $M$. mitchelli, the biomass dominants in this NRE benthic assemblage, declined by 90 to $100 \%$ over an area of $100.6 \mathrm{~km}^{2}$ (S.P.P. \& C.H.P. unpubl. data). This area of habitat degradation closely matched our maximal estimated extent of bottom-water hypoxia during that summer $\left(116 \mathrm{~km}^{2}\right)$. Macoma spp. is the most important benthic prey item for demersal fishes, crabs, and overwintering ducks in the NRE (S.P.P. \& C.H.P. unpubl. data). 
The ability to predict the spatial extent of bottom area exposed to hypoxia and subsequently the area of biological degradation is critical in understanding the ecological, management, and economic implications of hypoxia for estuarine systems. The degradation of benthic resources as a result of hypoxic waters can have significant impacts on energy transfers within the estuarine food web (Pihl et al. 1991, Peterson et al. 2000, Taylor \& Eggleston 2000). Given the dominance of many commercially and recreationally important fisheries species within estuarine food webs, most of which are demersal consumers, these defaunation events may have significant social and economic impacts (Peterson et al. 2000). Consequently, our ability to efficiently detect the onset and estimate the extent of hypoxic bottom-water is a necessary prerequisite to monitoring the physical and biological status of estuarine ecosystems.

Acknowledgements. We thank Crystal Fulcher for hydrographic analyses. We thank Pam Wyrick, Ben Peirels, Jennifer McNinch, and Crystal Fulcher for help with field sampling and maintenance of the long-term data set. We appreciate reviews provided by Janelle Fleming, Ben Peierls, Mike Piehler, Anna Kenne, and 4 anonymous reviewers. This study was funded by the United States Department of Agriculture (H.W.P. and J.L.P.), the North Carolina Sea Grant Program (H.W.P. and J.L.P.), the United States Environmental Protection Agency CISNet Program (R.A.L., H.W.P. and J.L.P.), and the Water Resources Research Institute of the University of North Carolina (R.A.L. et al.).

\section{LITERATURE CITED}

Bonham-Carter GF (1994) Geographic information systems for geoscientists: modelling with GIS. Pergamon Press, Tarrytown, NY

Borsuk M, Stow CA, Luettich RA, Paerl HW, Pinckney JL (2001) Probabilistic prediction of hypoxia in the Neuse River Estuary using an empirical model of oxygen dynamics. Estuar Coast Shelf Sci 52:33-49

Boyton WR, Kemp WM (1985) Nutrient regeneration and oxygen consumption by sediments along an estuarine salinity gradient. Mar Ecol Prog Ser 23:45-55

Breitburg DL (1990) Nearshore hypoxia in Chesapeake Bay: patterns and relationships among physical factors. Estuar Coast Shelf Sci 30:593-609

Breitburg DL (1992) Episodic hypoxia in Chesapeake Bay: interacting effects of recruitment, behavior, and physical disturbance. Ecol Monogr 62:252-546

Cerco CF, Cole T (1993) Three-dimensional eutrophication model of Chesapeake Bay. J Environ Eng 119:1006-1025

Diaz RJ, Rosenberg R (1995) Marine benthic hypoxia: a review of its ecological effects and the behavioural responses of benthic macrofauna. Oceanogr Mar Biol Annu Rev 33:245-303

Dortch Q, Rabalais NN, Turner RE, Rowe GT (1994) Respiration rates and hypoxia on the Louisiana shelf. Estuaries 17: 862-872

Falkowski PG, Hopkins TS, Walsh JJ (1980) An analysis of factors affecting oxygen depletion in the New York Bight.
J Mar Res 38:479-506

Fisher TR, Carlson PR, Barber RT (1982) Sediment nutrient regeneration in three North Carolina estuaries. Estuar Coast Shelf Sci 14:101-116

Holmer M (1999) The effect of oxygen depletion on anaerobic organic matter degradation in marine sediments. Estuar Coast Shelf Sci 48:383-390

Hopkinson CS, Giblin AE, Tucker J, Garritt RH (1999) Benthic metabolism and nutrient cycling along an estuarine salinity gradient. Estuaries 22:863-881

Kemp WM, Sampou PA, Garber J, Tuttle J, Boynton WR (1992) Seasonal depletion of oxygen from bottom-waters of Chesapeake Bay: roles of benthic and planktonic respiration and physical exchange processes. Mar Ecol Prog Ser 85:137-152

Kuo AY, Neilson BJ (1987) Hypoxia and salinity in Virginia estuaries. Estuaries 10:277-283

Kuo AY, Park K, Moustafa MZ (1991) Spatial and temporal variabilities of hypoxia in the Rappahannock River, Virginia. Estuaries 14: 113-121

Lenihan HS, Peterson CH (1998) How habitat degradation through fishery disturbance enhances impacts of hypoxia on oyster reefs. Ecol Appl 8:128-140

Lenihan HS, Peterson CH, Byers JE, Grabowski JH, Thayer GW, Colby DR (2001) Cascading of habitat degradation: oyster reefs invaded by refugee fishes escaping stress. Ecol Appl 11:764-782

Luettich RA, McNinch JE, Pinckney JL, Alperin M, Martens CS, Paerl HW, Peterson CH, Wells JT (2000) Neuse River Estuary Modeling and Monitoring Project: Monitoring Phase I Report. Water Resources Research Institute, Raleigh, NC

Matson EA, Brinson MM (1990) Stable carbon isotopes and the C:N ratio in the estuaries of the Pamlico and Neuse Rivers, North Carolina. Limnol Oceanogr 35:1290-1300

Nestlerode JA, Diaz RJ (1998) Effects of periodic environmental hypoxia on predation of a tethered polychaete, Glycera americana: implications for trophic dynamics. Mar Ecol Prog Ser 172:185-195

Nixon SW (1995) Coastal marine eutrophication: a definition, social causes, and future concerns. Ophelia 41:199-219

Officer CB, Biggs RB, Taft JL, Cronin LE, Tyler MA (1984) Chesapeake Bay anoxia: origin, development, and significance. Science 223:22-27

Paerl HW, Pinckney JL, Fear JM, Peierls BL (1998) Ecosystem responses to internal and watershed organic matter loading: consequences for hypoxia in the eutrophying Neuse River Estuary, North Carolina, USA. Mar Ecol Prog Ser 166:17-25

Peterson $\mathrm{CH}$, Summerson HC, Thomson E, Lenihan HS, Grabowski J, Manning L, Micheli F, Johnson G (2000) Synthesis of linkages between benthic and fish communities as a key to protecting essential fish habitat. Bull Mar Sci 66:759-774

Pihl L, Baden SP, Diaz RJ (1991) Effects of periodic hypoxia on distribution of demersal fish and crustaceans. Mar Biol 108:349-360

Rabalais NN, Wiseman WJ, Turner RE (1994) Comparison of continuous records of near-bottom dissolved oxygen from the hypoxia zone along the Louisiana coast. Estuaries 17: 850-861

Rizzo WM, Christian RR (1996) Significance of subtidal sediments to heterotrophically mediated oxygen and nutrient dynamics in a temperate estuary. Estuaries 19:475-487

Sanford LP, Sellner KG, Breitburg DL (1990) Covariability of dissolved oxygen with physical processes in the summertime Chesapeake Bay. J Mar Res 48: 567-590

Seliger HH, Boggs JA, Biggley WH (1985) Catastrophic 
anoxia in Chesapeake Bay in 1984. Science 228:70-73

Stanley DW (1993) Long-term trends in Pamlico River Estuary nutrients, chlorophyll, dissolved oxygen, and watershed nutrient production. Water Res Res 29:2651-2662

Stanley DW, Nixon SW (1992) Stratification and bottomwater hypoxia in the Pamlico River Estuary. Estuaries 15: 270-281

Surfer (1999) Surfer 7.0 user's guide. Golden Software, Golden, CO

Taylor DL, Eggleston DB (2000) Effects of hypoxia on an estuarine predator-prey interaction: foraging behavior and mutual interference in the blue crab Callinectes sapidus

Editorial responsibility: Lisa Levin (Contributing Editor),

La Jolla, California, USA and the infaunal clam prey Mya arenaria. Mar Ecol Prog Ser 196:221-237

Tenore KR (1972) Macrobenthos of the Pamlico River Estuary, North Carolina. Ecol Monogr 42:51-69

Turner RE, Schroeder WW, Wiseman WJ (1987) The role of stratification in the deoxygenation of Mobile Bay and adjacent shelf bottom-waters. Estuaries 10:13-19

Tyson RV, Pearson TH (1991) Modern and ancient continental shelf anoxia. Geol Soc Spec Publ No. 58

Welsh BL, Eller FC (1991) Mechanisms controlling summertime oxygen depletion in western Long Island Sound. Estuaries 14:265-278

Submitted: January 2, 2001; Accepted: August 15, 2001 Proofs received from author(s): March 8, 2002 